\title{
Parasitosis ilusoria intestinal y dermatológica: casos clínicos
}

\author{
Edith Pérez de Arce, Daniela Rosset, Mario Arcos, Douglas Castillo, Carlos Gil, Caroll Beltrán y Luis Carlos Gil
}

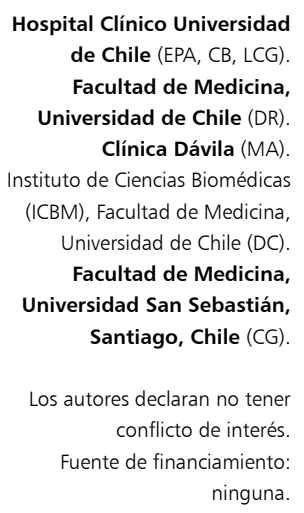

Recibido: 26 de octubre de 2016 Aceptado: 15 de abril de 2017

Correspondencia a: Luis Carlos Gil La Rotta drlcgill@yahoo.com

\section{Introducción}

L a parasitosis ilusoria, también conocida como delusión parasitaria o falsa parasitosis es un síndrome, generalmente neuropsiquiátrico, donde el paciente está convencido de estar infestado por parásitos. Sin embargo, cuando se realiza la evaluación clínica y/o exámenes de laboratorio no se encuentran elementos parasitarios o parásitos que confirmen una infestación ${ }^{1,2}$.

La parasitosis ilusoria es un motivo de consulta poco frecuente y sólo se conoce por comunicaciones de series de $\operatorname{casos}^{3-6}$, por lo que se desconoce su real prevalencia. Otras denominaciones encontradas en la literatura para este cuadro son: delirio parasitario, entomofobia, parasitofobia, síndrome de Ekbom y más recientemente, enfermedad de Morgellons ${ }^{1,2}$.

En nuestro medio, es una entidad poco conocida entre médicos no parasitólogos. A continuación, se presentan cuatro casos de pacientes que consultaron a distintos médicos por esta singular condición, sin lograr un diagnóstico definitivo y que fueron aclarados luego de evaluación por un médico parasitólogo.

\section{Caso clínico 1}

Mujer de 54 años, con antecedentes de bulimia diagnosticada en la adolescencia, sin uso reciente de fármacos. La paciente consultó por una historia de dolor abdominal intermitente y flatulencias desde hacía cinco años que fueron atribuidos a un síndrome de intestino irritable.

En el último año, la paciente había percibido una baja de peso de aproximadamente cinco kilos. En los últimos seis meses, había sido evaluada reiteradamente en el servicio de urgencias por náuseas, vómitos y deposiciones que describía como sanguinolentas. Además, refería estar preocupada por haber expulsado "gusanos" en sus deposiciones, los que coleccionó en un frasco para mostrarle al médico gastroenterólogo. La muestra de deposiciones fue analizada en parasitología por sospecha de teniasis.

Se realizaron exámenes de laboratorio clínico generales que fueron normales. Además, se realizó un TC de abdomen y pelvis que no presentó hallazgos significativos. La endoscopia digestiva alta mostró una gastritis erosiva leve, sin signos de hemorragia y la colonoscopia con ileoscopia distal fue normal.

Por persistencia de los síntomas, la paciente consultó a un parasitólogo a quien le manifestó la expulsión anal de membranas alargadas. Durante la entrevista clínica, la paciente refirió no consumir carnes crudas de cerdo, vacuno o salmón. Se solicitó un estudio parasitológico seriado de deposiciones (EPSD) y un test de Graham, ambos con resultados negativos. Finalmente, el examen macroscópico del "gusano" llevado por la paciente al laboratorio de parasitología resultó ser una babosa de jardín del género Limax (Figura 1). La paciente manifestó gran resistencia a la comprensión de los hallazgos y se le indicó evaluación psiquiátrica, la cual rechazó.

\section{Caso clínico 2}

Mujer de 45 años, con antecedentes de depresión en tratamiento con fluoxetina. La paciente refirió la expul- 
sión por el ano de "bichitos" que caminaban por todo su cuerpo. El médico solicitó un EPSD, test de Graham y acarotest, los tres con resultado negativo. La paciente acudió al médico internista, quien le indicó empíricamente albendazol $400 \mathrm{mg}$ por dos días y la derivó a dermatología. El dermatólogo solicitó nuevas muestras de deposiciones, todos negativos para parásitos intestinales y ectoparásitos, por lo que la paciente fue derivada al parasitólogo. Al interrogatorio dirigido, ella refería que vivía en una casa urbanizada y que no tenía mascotas por miedo a contagiarse con "bichos". Además, negaba actividad sexual por temor a infestarse con los "bichos" de su pareja, y tampoco recibía visitas ya que podían estar cursando con infecciones intestinales o cutáneas. Al examen físico, no se evidenciaban lesiones de la piel ni anexos. A la consulta llevó los "bichos" que capturó en un trozo de papel higiénico. El examen macroscópico de los "bichos" correspondía a una mezcla de restos de pan rallado y arena. Tras no objetivarse una parasitosis y por la persistencia en la falsa creencia de infestación parasitaria, se recomendó a la paciente una evaluación psiquiátrica, la cual rechazó.

\section{Caso clínico 3}

Varón de 68 años, con antecedentes de hipertensión arterial y enfermedad renal crónica en hemodiálisis hacía cinco años. Hacía un año percibía que por su cuerpo se desplazaban insectos pequeños, los cuales escasamente podía ver y que le ocasionaban prurito.

El paciente fue evaluado reiteradamente por diferentes médicos (generales, internistas y nefrólogos) sin lograr demostrarse la presencia de parásitos. Consultó también a un dermatólogo que no evidenció lesiones al examen físico. Además, el EPSD, test de Graham y acarotest fueron negativos. Al no encontrar una explicación a sus síntomas, que él consideraba que eran ocasionados por "parásitos", solicitó ser evaluado por un especialista parasitólogo. Al examen físico sólo evidenciaba escoriaciones en antebrazos y muslos atribuibles al grataje. El nuevo estudio parasitológico, al igual que cinco estudios previos fueron negativos. Finalmente, se sugirió al paciente una evaluación con psiquiatra, lo que desencadenó su enojo y la frase: "no estoy loco y el parasitólogo no sabe nada de bichos".

\section{Caso clínico 4}

Mujer de 54 años, dueña de casa, profesional, con antecedente de un trastorno del ánimo en el contexto de una separación conyugal. Además, señalaba que le gustaba realizar actividades de jardinería en su domicilio.

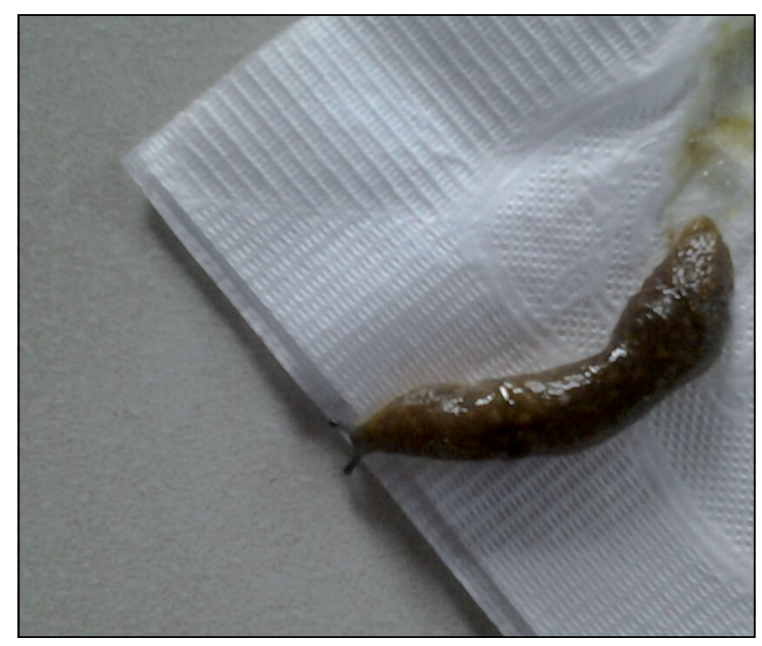

Figura 1. Babosas del género Limax. Babosa llevada a la consulta por la paciente correspondiente al caso 1.

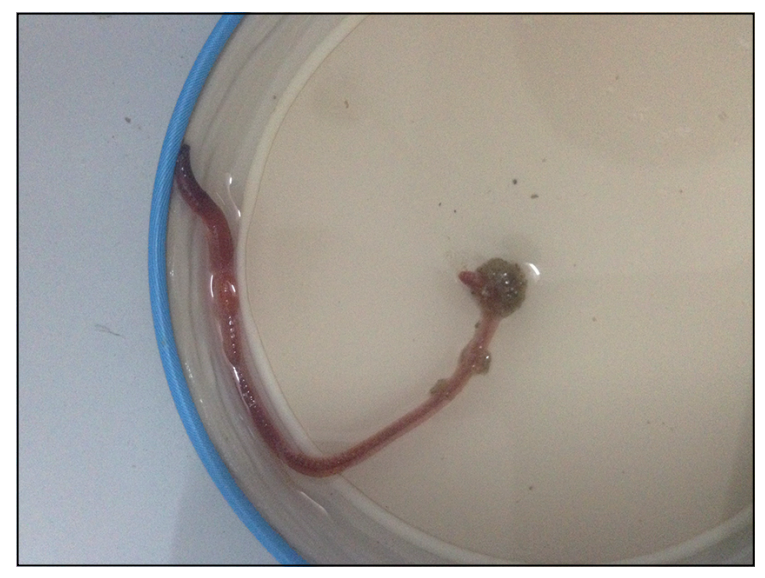

Figura 2. Lombriz de tierra, Lombricus terrarius. Lombriz llevada a la consulta por la paciente del caso 4.
La paciente refirió expulsar una "lombriz" en sus deposiciones. Fue evaluada por un médico internista quien la trató en forma empírica con albendazol $400 \mathrm{mg}$ por día, durante 15 días.

El EPSD y test de Graham fueron negativos. El examen macroscópico del verme llevado a la consulta por la paciente correspondió a una lombriz de tierra o Lombricus terrarius (Figura 2). Un mes después, la paciente volvió a consultar por haber eliminado por las deposiciones una nueva "lombriz". Fue tratada con albendazol por 15 días, con un nuevo estudio parasitológico sin hallazgos. El verme fue analizado en el Instituto de Salud Pública y se confirmó el diagnóstico inicial.

Dos meses después, la paciente refirió que al ducharse notó la expulsión de una lombriz por el ano, que resultó ser similar a las anteriores. El estudio en el laboratorio de parasitología del espécimen informó nuevamente una 
lombriz de tierra. La paciente, muy molesta, reclamó que nadie encontraba una solución a su mal en Chile, por lo que consultaría en otro país. Se le recomendó la evaluación por psiquiatría, sin embargo, se negó a considerar esta alternativa.

\section{Discusión}

La parasitosis ilusoria o delusión parasitaria forma parte de un cuadro conocido hoy como infestación delusoria, redefinida en el año 2009 por Freudenmann y Lipping ${ }^{1}$. Esta última definición incluye la percepción de objetos animados (bacterias, virus, hongos, parásitos) y también objetos inanimados (fibras, filamentos, pelos, partículas). Se ha descrito como un trastorno de la esfera psiquiátrica, en relación a cuadros de psicosis monosintomática asociada a esquizofrenia, trastornos obsesivos compulsivos, trastornos bipolares y depresión, entre otros ${ }^{1,2,7}$.

A pesar de ser más frecuente en pacientes psiquiátricos, también se ha visto en trastornos orgánicos como la enfermedad renal crónica avanzada, cirrosis hepática avanzada, diabetes mellitus, hipotiroidismo, hipovitaminosis B12, enfermedades neurológicas con compromiso tipo demencia o cuadros que causan alucinaciones, en algunas toxicomanías principalmente por cocaína, anfetaminas, marihuana y alcohol, entre otras ${ }^{2,8,9}$. Se ha descrito con mayor frecuencia en pacientes de sexo femenino en una relación 2,5:1, y la edad de mayor prevalencia oscila entre los 40 y 60 años 6,10 .

Desde el punto de vista cultural y social, la parasitosis ilusoria se describe en todos los estratos y en toda clase de oficios y profesiones. Son pacientes que tradicionalmente acuden a consultar a diferentes médicos y especialistas, al igual que suelen relatar diferentes tipos de historias clínicas a los médicos evaluadores ${ }^{1,11}$. En un estudio de Hylwa y cols., de la clínica Mayo ${ }^{12}, 43 \%$ de los casos de parasitosis facticia consultaron al dermatólogo, 19\% al servicio de urgencias, $17 \%$ al médico internista, $4 \%$ al médico de familia y $13 \%$ a otras especialidades, pero ninguno de ellos consultó en primera instancia al psiquiatra. Además, un alto porcentaje no aceptó ir a la consulta psiquiátrica cuando ésta fue sugerida ${ }^{13}$.

Los principales motivos de consulta en la parasitosis ilusoria son la visualización de "bichos, gusanos o insectos" que se mueven en o bajo la piel. Según los pacientes, algunos de estos "bichos" son imposibles de capturar pues son demasiado pequeños y de gran movilidad. Los síntomas más frecuentes son prurito, eritema, escoriaciones, principalmente en manos, brazos, espalda, abdomen y genitales. Menos frecuentemente consultan por la presencia de "gusanos o bichos" en orificios como la boca, nariz, ano o la expulsión de vermes a través del tubo digestivo. Se ha descrito en la literatura científica el "signo del espécimen" "3,14, presente en $25-75 \%$ de los pacientes, y que consiste en que los sujetos llevan una muestra del espécimen del cual creen estar infestados a la consulta médica, en algún medio de transporte (contenedores de vidrio, bolsas, tapas, cajas, papel higiénico, etc.). En ocasiones suelen llevar restos de pelo, costras, hilos, materia orgánica como fibras, vegetales o materia inorgánica como arena y tierra en pequeñas cajas de cartón, de ahí la denominación de "síndrome de la caja de fósforos"15.

En la anamnesis, estos pacientes suelen referir que probablemente se contagiaron por contacto directo con otras personas, que ellos creen están infestados con parásitos obtenidos del contacto con plantas, mascotas, tierra o por el consumo de alimentos no adecuadamente desinfectados. Algunos pacientes, al no obtener una respuesta satisfactoria al trastorno que los aqueja, suelen automedicarse con fármacos para posibles parasitosis intestinales o se aplican cremas o ungüentos cuando creen padecer una dermoparasitosis y en algunos casos, usan productos tóxicos sobre la piel como agua de batería, pinturas y solventes orgánicos entre otros ${ }^{16}$. El trauma de la piel ocasionado por estos productos puede llegar en algunos casos a automutilaciones cuando los pacientes tratan de eliminar lo que ellos consideran es un parásito no reconocido por su médico ${ }^{17,18}$.

El enfoque del estudio y terapia tras sospechar el síndrome debe ser cuidadoso ${ }^{14}$ y los objetivos son: mejorar la condición del paciente, esto es no intentar por todos los medios convencerlo de que tiene una falsa creencia; realizar una historia clínica (uso de fármacos, drogas, alcohol, comorbilidades, consultas médicas previas) y un examen físico exhaustivo.

Escuchar las molestias, frustraciones y emociones del paciente en relación a su padecimiento en forma atenta y asertiva permitirán un mayor acercamiento. Se debe realizar una alianza con el paciente para diseñar un plan de estudio racional dirigido a descartar organicidad y las posibles propuestas de manejo si el estudio resulta ser negativo. Derivar al psiquiatra oportunamente ${ }^{19}$, como parte del enfoque multidisciplinario y del plan terapéutico propuesto. Finalmente, el psiquiatra será el encargado del manejo de especialidad y de la indicación de antipsicóticos ${ }^{20} \mathrm{o}$ antidepresivos cuando estos correspondan.

En conclusión, la parasitosis ilusoria requiere un alto índice de sospecha clínica cuando el paciente es policonsultante tras creer que se padece una parasitosis, contando un relato poco concordante y cuando ha sido ampliamente estudiado por profesionales médicos sin arrojar resultados positivos. Se debe ser cuidadoso en la forma de enfrentar a estos pacientes para lograr una derivación adecuada y asertiva al psiquiatra y evitar una mayor frustración y angustia en ellos. 


\section{Resumen}

La parasitosis ilusoria, más conocida como delusión parasitaria, es un síndrome neuropsiquiátrico donde los pacientes tienen el convencimiento de padecer una infestación parasitaria, que no puede ser demostrada tras un exhaustivo estudio médico. Estos pacientes se caracterizan por ser policonsultantes en distintas especialidades médi- cas y, muchos de ellos, poseen antecedentes de trastornos psiquiátricos, algunos de ellos no diagnosticados. Conocer la existencia del cuadro, diagnosticar precozmente y empatizar con el paciente, pueden dar al médico clínico algunas claves para una derivación psiquiátrica oportuna y asertiva, y mejorar la adherencia del paciente al tratamiento propuesto. Se presentan cuatro casos clínicos que consultaron por esta extraña condición.

\section{Referencias bibliográficas}

1.- Freudenmann R W, Lepping P. Delusional infestation. Clin Microbiol Rev 2009; 22: 690732.

2.- Hinkle N C. Delusory parasitosis. Am Entomol 2000; 46: 17-25.

3.- Freudenmann R, Lepping P, Huber M, Dieckmann S, Bauer-Dubau K, Ignatius R, et al. Delusional infestation and the specimen sign: a European multicentre study in 148 consecutive cases. Br J Dermatol 2012; 167: 247-51.

4.- Bailey C H, Andersen L K, Lowe G C, Pittelkow M R, Bostwick J M, Davis M D. A population-based study of the incidence of delusional infestation in Olmsted County, Minnesota, 1976-2010. Br J Dermatol 2014; 170: 1130-5.

5.- Tran M M, Iredell J R, Packham D R, O'Sullivan M V, Hudson B J. Delusional infestation: an Australian multicentre study of 23 consecutive cases. Intern Med J 2015; 45 : 454-6.

6.- Trabert W. 100 years of delusional parasitosis. Meta-analysis of 1,223 case reports. Psychopathology 1995; 28: 238-46.
7.- $\quad$ Bhatia M S, Jagawat T, Choudhary S. Delusional parasitosis: a clinical rofile. Int J Psychiatry Medicine 2000; 30: 83-91.

8.- Moreno Vázquez K, Ponce Olivera M, Narváez Rosales V, Ubbelohde Hennigsen T. Síndrome de Ekbom. Dermatología Rev Mex 2007; 51: 51-6.

9.- Calvo Estopiñán P. Delirio de formicación. A propósito de un caso. Psiquiatría Biológica 2010; 17: 138-9.

10.- Madoz-Gúrpide A, García Resa E. Delirio parasitario dermatozoico. Medicina Clínica 2004; 123: 66-9.

11.- Boggild A K, Nicks B A, Yen L, Van Voorhis W, McMullen R, Buckner F S, Liles W C. Delusional parasitosis: six-year experience with 23 consecutive cases at an academic medical center. Int J Infect Dis 2010; 14: e317-21.

12.- Hylwa S A, Bury J E, Davis M D, Pittelkow M, Bostwick J M. Delusional infestation, including delusions of parasitosis: results of histologic examination of skin biopsy and patientprovided skin specimens. Arch Dermatol 2011; 147: 1041-5.

13.- Soderfeldt $Y$, Grob D. Information, consent and treatment of patients with Morgellous disease: an ethical perspective. Am J Clin Dermatol 2014; 15: 71-6.

14.- Heller M M, Wong J W, Lee E S, Ladizinski B, Grau M, Howard J L, et al. Delusional infestations: clinical presentation, diagnosis and treatment. Int J Dermatol 2013; 52: 775-83.

15.- Leal C, Oliveira T, Rodrigues A, Freitas C. Delusional parasitosis and bipolar disorder: case report. Rev Psiquiatr Rio Gd Sul 2009; 31: 79-81.

16.- Lee W R. Matchbox sign. Lancet 1983; 2 (8347): 457-8

17.- Ash L, Orihel T. Parasitosis ilusoria. Atlas de Parasitología Humana. $5^{\circ}$ edición. Editorial Panamericana 2007: 386-7.

18.- Torales J, Arce A, Bolla L, González L, Martino B D, Rodríguez M, et al. Delirio parasitario dermatozoico. Reporte de un caso. Anales de la Facultad de Ciencias Médicas 2015; 44: 81-8.

19.- Alonzo Romero L, Fernández y de la Borbolla R, Campos Fernández M, Espinosa L. Delirio de parasitosis. Dermatología Rev Mex 2008; 52: 263-7.

20.- Lepping P, Russell I, Freudenmann R W. Antipsychotic treatment of primary delusional parasitosis. Br J Psychiatry 2007; 191: 198-205. 